\title{
Faecal stasis and diverticular disease in ulcerative colitis
}

K. N. JALAN, R. J. WAlker, R. J. PRESCOTT, S. T. G. BUtTERWORTh, A. N. SMITH, AND W. SIRCUS

From the Gastrointestinal Unit, and the Department of Pathology, Western General Hospital, Edinburgh, and the Computer and Statistics Section, Department of Social Medicine, Universityof Edinburgh

SUMMARY The incidence of faecal stasis and of diverticular disease has been studied in a group of 399 patients with ulcerative colitis. Sixty-one patients had faecal stasis and 23 patients had diverticular disease. Pathological studies demonstrated an increase in the thickness of the inner spiral muscle in colitis patients with faecal stasis. The thickening was not as great as that seen in diverticular disease. Preliminary studies on the motility patterns in patients with faecal stasis show a higher mean activity in the pelvic colon than in normals but not as great as that seen in diverticular disease. Pressure studies in patients with faecal stasis have shown hypotonia in the proximal colon associated with dilatation.

The possible significance of these results is discussed. It is suggested that ulcerative colitis may initiate a motility disturbance which leads to muscle thickening similar to that in diverticular disease. Diverticula associated with ulcerative colitis are usually not involved in the mucosal inflammatory process.

It is recognized that constipation may occur in patients with proctocolitis (Royal Society of Medicine, 1909; Sim and Brooke, 1958; Nefzger and Acheson, 1963; Goligher, de Dombal, Watts, and Watkinson, 1968), and in up to one third of patients with proctitis (Lennard-Jones, Cooper, Newell, Wilson, and Jones, 1962a). Constipation as a prominent disability was described in six patients with distal proctocolitis all of whom had severe disease with retention of faeces in the proximal colon (Lennard-Jones, Langman, and Jones, 1962b).

We have studied this association as part of a retrospective survey involving 399 patients with ulcerative colitis (Jalan, Prescott, Sircus, Card, McManus, Falconer, Small, Smith, and Bruce, 1909). In view of the possibility that the cause of the constipation could be in disordered motor activity of the large bowel, we have examined the incidence and possible significance of diverticular disease when this occurred in association with ulcerative colitis. Differences have been sought in the clinical and pathological features of those colitis patients with constipation, both Received for publication 24 December, 1969. with and without diverticular disease, from those of the remainder of the series. Large bowel motility was studied in a small number of patients.

\section{Method}

The retrospective study covers the period 1950 to 1967 (inclusive). The primary source of the data was the case records, the information being transferred to cards and the material analysed by Atlas computer.

The diagnosis of faecal stasis in colitis was made when a change of bowel habit occurred becoming less frequent than normal and/or the need for laxatives. Radiological evidence of faeces in the proximal colon was usually obtained. Barium often persisted in the right half of the colon a week or even a month after a barium enema (Figs. 1 and 2). Diverticular disease was diagnosed on the presence of one or more diverticula with or without radiological evidence of motor or inflammatory abnormality in the colon. In the whole series there were 173 males and 226 


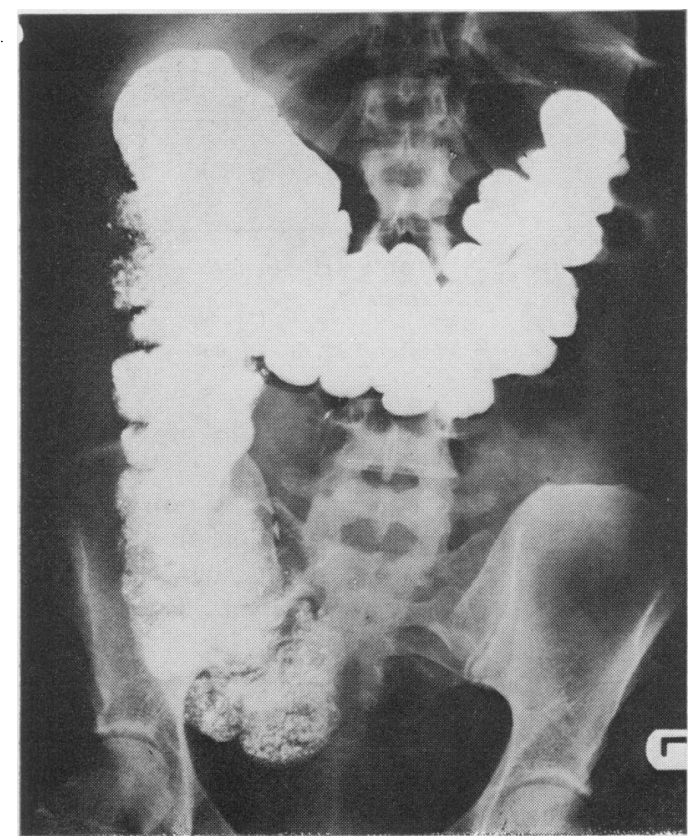

Fig. 1 Barium mass in the ascending colon in a patient with faecal stasis one day after barium enema.

females. One hundred and ninety-one patients were in a first attack of colitis and 208 in relapse.

\section{MOTILITY STUDIES}

Motor activity of the proximal colon was assessed in eight patients and four controls using a radiotelemetering capsule (Solartron capsule); pressure waves were recorded from the frequency change, 'movement activity' from the signal strength, and progression from the change in the 'edge' of the radiomagnetic field (Smith and Ridgway, 1962).

Pressure activity in the sigmoid zone and rectum was examined in five paticn:s with faecal stasis, 29 patients with uncomplicated diverticular disease, and in 14 control subjects by peranal passage of miniature balloons on air-filled polythene tubes. These were connected by Statham transducers to electromanometers within a photorecording device; basal tone was recorded and meals or prostigmine $(0.5-1 \mathrm{mg})$ were used as stimuli.

\section{PATHOLOGY}

Histological material from 15 patients with faecal stasis was available for study. Studies of the colons of 26 patients with ulcerative colitis but without faecal stasis served as controls. The intact specimens of resected colon were not available at the time of this study, but the pathologists' original reports of the microscopic appearances of these were analysed and considered,

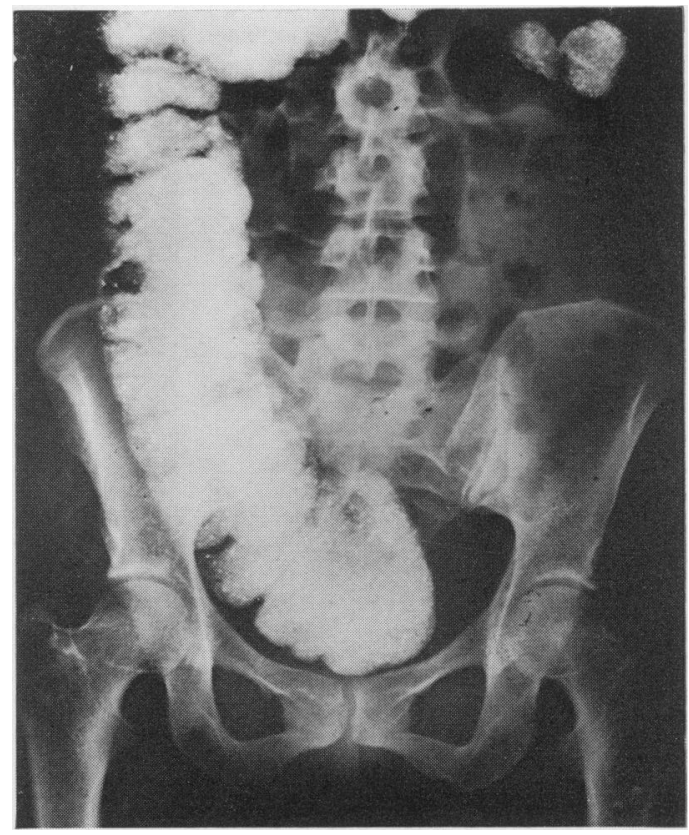

Fig. 2 Same patient as in Figure 1. Barium mass still present 18 days later.

together with a review of the remaining blocks and sections from known sites in the colon. An eye-piece micrometer was used to measure the maximum thickness of the circular muscle coat in sections from the descending and sigmoid colon.

\section{Results}

\section{CLINICAL ASSESSMENT}

\section{Incidence}

Faecal stasis was present in $15.8 \%$ of patients with ulcerative colitis. In some cases constipation was the major source of disability and such patients correspond to those described by Lennard-Jones et al (1962b). Of 79 patients with disease confined to the rectum, 21 had stasis. This incidence of $26.6 \%$ is similar to that reported by Lennard-Jones and his colleagues (1962a) in proctitis. It is rare in the young (Fig. 3).

We also confirmed the commoner incidence of faecal stasis in females (Table I). Five out of the six cases of stasis described by LennardJones et al (1962b) were female.

\section{Previous history}

Twenty per cent of the patients with faecal stasis reported constipation before the onset of colitis compared with $5.3 \%$ of the patients without stasis. It is emphasized that a history of 
K. N. Jalan, R. J. Walker, R. J. Prescott, S. T. G. Butterworth, A. N. Smith, and W. Sircus

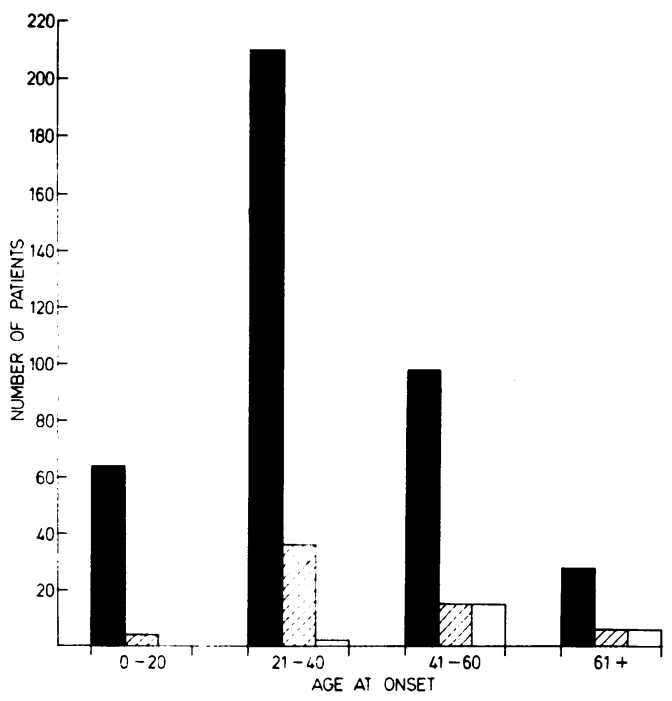

Fig. 3 Age incidence of faecal stasis (shaded area) and diverticular disease (unshaded) associated with ulcerative colitis. The total number of patients is shown by the black areas.

\begin{tabular}{lll}
\hline \multirow{2}{*}{ Sex } & Faecal Stasis & \\
\cline { 2 - 3 } & With & Without \\
\hline Male & 18 & 155 \\
Female & 43 & 183 \\
\hline
\end{tabular}

Table I Sex incidence in patients with faecal stasis ${ }^{1}$ ${ }^{1} x^{2}=4.98, \mathrm{df}=1,0.025<\mathrm{P}<0.05$.

constipation is subjective. Frequencies shown are of visits to the lavatory (Table II). Faeces are not always passed on each occasion but often only mucus, mucopus, or blood without faeces.

\begin{tabular}{lll}
\hline No. of Motions & \multicolumn{2}{l}{ Faecal Stasis } \\
\cline { 2 - 3 } & With & Without $^{1}$ \\
\hline $0-4$ & 17 & 70 \\
$5-8$ & 33 & 153 \\
$9+$ & 11 & 113 \\
\hline
\end{tabular}

Table II Frequency of bowel motion in patients with faecal stasis $^{2}$

${ }^{1}$ In two patients bowel frequency was not recorded. ${ }^{2} x^{2}=6.00, \mathrm{df}=2,0.025<\mathrm{P}<0.05$.

\section{Length of history}

Stasis is relatively more common in patients with disease of short duration (Table III), and incidence is the same in the first attacks as in relapses and in colitis of gradual or sudden onset.

Severity, extent, and prognosis

A scoring procedure was used to classify patients

\begin{tabular}{lll}
\hline $\begin{array}{l}\text { Length of History } \\
(y r)\end{array}$ & Faecal Stasis \\
\cline { 2 - 3 } & With & Without \\
\hline$<1$ & 35 & 159 \\
$1-9$ & 13 & 123 \\
$10+$ & 13 & 56 \\
\hline
\end{tabular}

Table III Length of history in patients with faecal stasis $^{1}$

${ }^{1} \chi^{2}=5.25, \mathrm{df}=2,0.05<\mathrm{P}<0.1$.

into three grades of severity: mild, moderate, and severe (Jalan et al, 1969). The variables used were fever, number of bowel movements, and erythrocyte sedimentation rate. A significant relationship between stasis and severity of disease was not established (Table IV). A larger proportion

\begin{tabular}{lll}
\hline \multirow{2}{*}{ Severity } & \multicolumn{2}{l}{ Faecal Stasis } \\
\cline { 2 - 3 } & With & Without \\
\hline Mild & 34 & 156 \\
Moderate & 15 & 83 \\
Severe & 12 & 109 \\
\hline
\end{tabular}

Table IV Severity of colitis in patients with faecal stasis $^{1}$

${ }^{1} \chi^{2}=3 \cdot 72, \mathrm{df}=2,0 \cdot 10<\mathrm{P}<0 \cdot 20$.

of patients with faecal stasis had a normal barium enema or partial 'left-sided' colitis as compared with the remaining patients (Table V). Faecal stasis was observed in only seven subjects with extensive involvement of the colon. Likewise the incidence of colonic stricture and of toxic

\begin{tabular}{llc}
\hline \multirow{2}{*}{ Extent } & \multicolumn{2}{l}{ Faecal Stasis } \\
\cline { 2 - 3 } & With & Without \\
\hline Normal & 21 & 58 \\
Partial left ${ }^{1}$ & 31 & 118 \\
Entire & 7 & 124 \\
Not known & 2 & 38 \\
\hline
\end{tabular}

Table $\mathrm{V}$ Extent of bowel involvement (radiological) in patients with faecal stasis ${ }^{2}$

${ }^{1}$ Includes 10 patients with right-sided and segmental colitis two of which are in the group of patients with faecal stasis.

${ }^{2} \chi^{2}=24.56, \mathrm{df}=3, \mathrm{P}=<0.0005$

dilatation was less than that found in the subjects without stasis (Table VI). Not surprisingly, therefore, the outcome in patients with faecal stasis is good so that the phenomenon is predominantly an expression of the better prognosis of subjects with distal involvement regardless of the severity of the attack (Table VII). Furthermore a higher proportion of patients with stasis show decreasing severity with time, and a smaller number exhibit continuous disease as compared with the nonstasis group. 


\begin{tabular}{|c|c|c|}
\hline \multirow{2}{*}{ - } & \multicolumn{2}{|c|}{ Faecal Stasis } \\
\hline & With & Without \\
\hline $\begin{array}{l}\text { Colonic stricture } \\
\text { No colonic stricture }\end{array}$ & $\left.\begin{array}{l}1 \\
60\end{array}\right\}$ & $\begin{array}{r}17 \\
321\end{array}$ \\
\hline $\begin{array}{l}\text { Toxic dilatation } \\
\text { No toxic dilatation }\end{array}$ & $\left.\begin{array}{r}3 \\
58\end{array}\right\}$ & $\begin{array}{r}52 \\
286\end{array}$ \\
\hline
\end{tabular}

Table VI Toxic dilatation and colonic stricture in relation to faecal stasis ${ }^{1}$

${ }^{1} \mathbf{P}>0.1$ (exact test)

${ }^{2} \chi^{2}=3.93, \mathrm{df}=1,0.025<\mathrm{p}<0.05$.

\begin{tabular}{lll}
\hline Outcome & \multicolumn{2}{l}{ Faecal Stasis } \\
\cline { 2 - 3 } & With & Without \\
\hline Clinical remission & 53 & 211 \\
Improved & 3 & 20 \\
Surgical survivors & 5 & 74 \\
Death & & 16 \\
Medical treatment & 0 & 17 \\
After surgery & 0 & 338 \\
Total & 61 & \\
\hline
\end{tabular}

Table VII Outcome of first referred attack in patients with faecal stasis

${ }^{1}$ All patients undergoing surgery had had previous medical treatment.

Twenty-three patients in whom colitis and diverticular disease coincided were similarly analysed. Seven of these had faecal stasis. The incidence of faecal stasis in patients with colitis and diverticular disease is not different from the rest of the population of colitis. In respect of sex, age at onset, previous bowel habit, site of attack, onset of colitis, extent of involvement, severity, and prognosis, no differences emerge from those

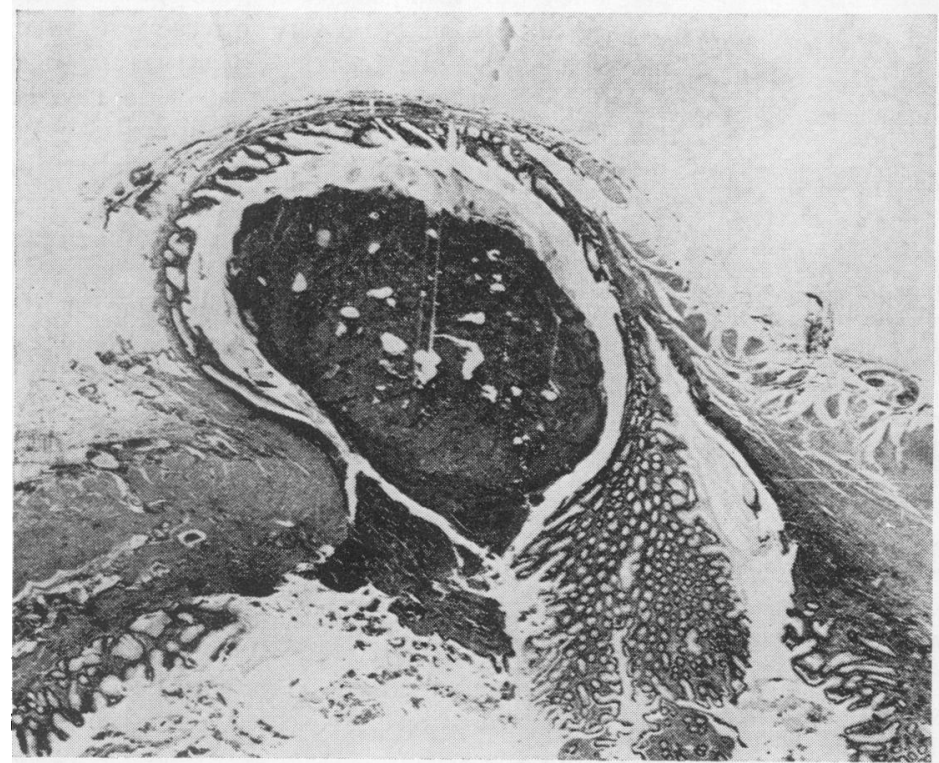

Fig. 4 characteristics in the group of colitics without diverticular disease.

\section{PATHOLOGY}

The incidence of pericolitis, submucosal fibrosis, and destruction of ganglion cells was the same in the two groups of patients with and without stasis. As already shown in the clinical assessment, the proportion of patients with limited or distal colitis was much greater in the group of patients with faecal stasis and proximal dilatation of the colon was much commoner. In the latter subjects, the mucosa of the proximal colon tended to be rather thin, but only in three was this a notable feature $(<0.3 \mathrm{~mm})$; all had associated diverticular disease.

It is of interest that in three patients the inflammatory changes of ulcerative colitis were slight or absent in the mucosal portion of the diverticula (Figs. 4 and 5). Of six patients with colitis and with diverticular disease and faecal stasis, in only three was the diagnosis of diverticular disease made by radiology. Only one patient had an organic obstruction, a kink in the bowel apparently caused by pericolic fibrosis.

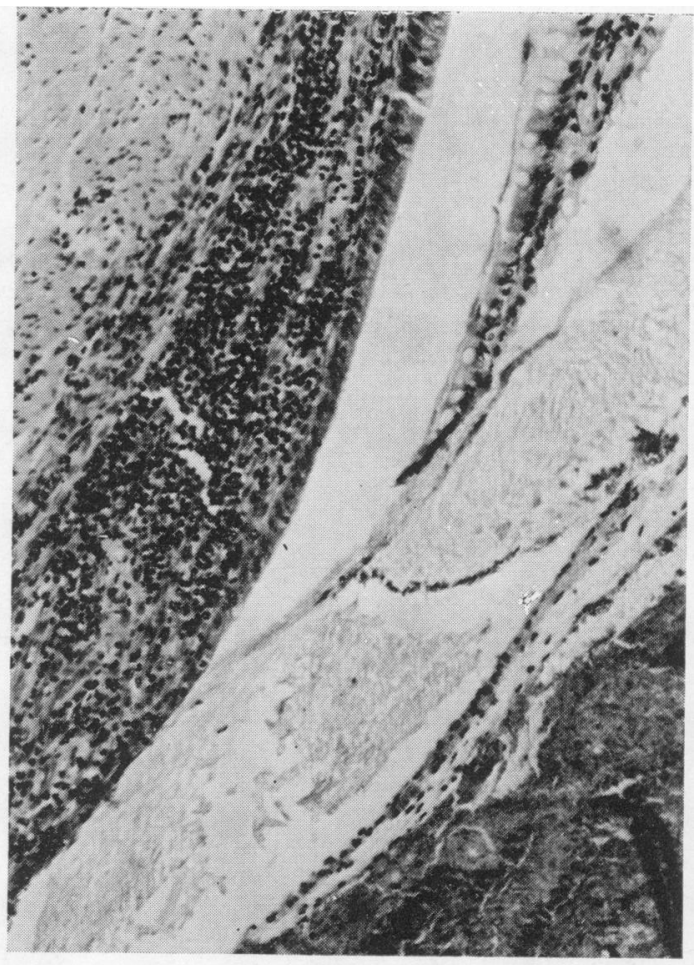

Fig. 5

Figs. 4 and 5 Diverticulum (left) in a case of ulcerative colitis. Inflamed mucosa and granulation tissue can be seen at the neck, but the inflammation does not extend into the compressed diverticular mucosa $(\times 15$, haematoxylin and eosin). Magnified (above) view of junction of compressed and inflamed areas. $(\times 75$, haematoxylin and eosin). 


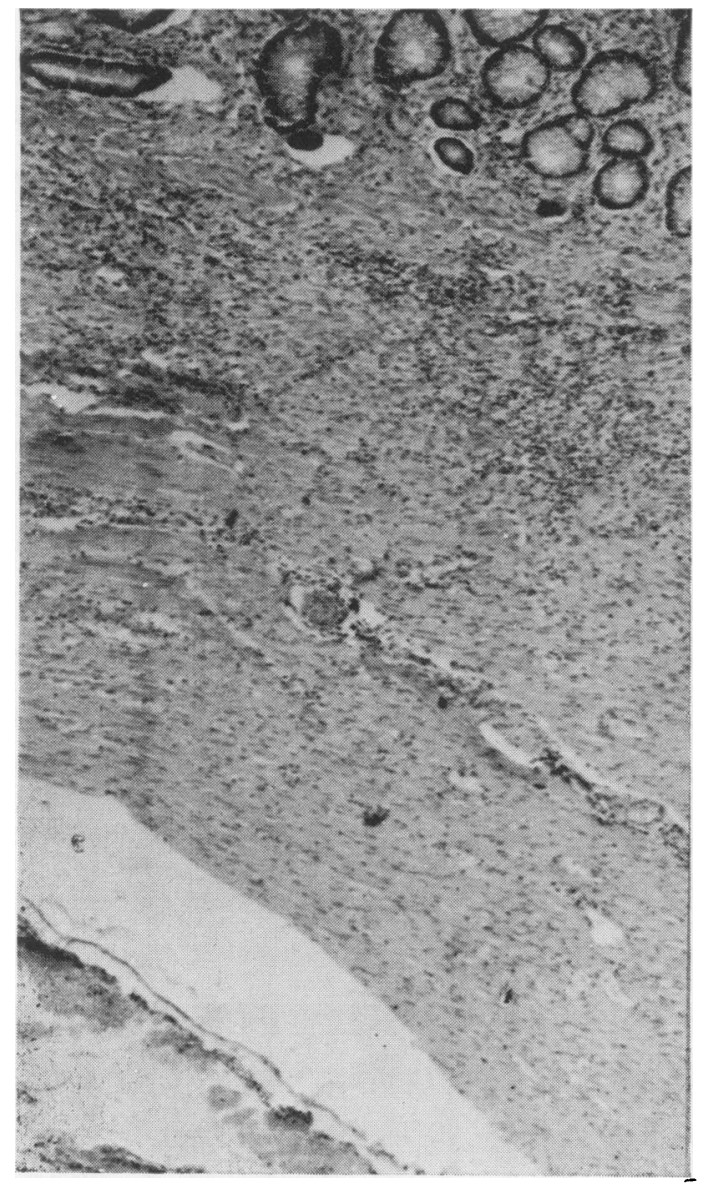

Fig. 6 Descending colon in a case of ulcerative colitis and faecal stasis, but without diverticular disease, to illustrate the thickness $(1.8 \mathrm{~mm})$ of the muscular coat $(\times 40$, haematoxylin and eosin $)$.

\begin{tabular}{|c|c|c|c|}
\hline & \multicolumn{3}{|l|}{ Group } \\
\hline & $\begin{array}{l}1 \text { (Control) Ulcerative } \\
\text { Colitis Only }\end{array}$ & $\begin{array}{l}2 \text { Faecal Stasis with } \\
\text { Ulcerative Colitis }^{1}\end{array}$ & $\begin{array}{l}3 \text { (Control) Diverticular } \\
\text { Disease Only }\end{array}$ \\
\hline No. of patients & 26 & 15 & 15 \\
\hline $\begin{array}{l}\text { Muscle thickness ( } m \\
\text { Range } \\
\text { Mean } \\
\text { SD }\end{array}$ & $\begin{array}{l}m) \\
0 \cdot 6-2 \cdot 1 \\
1 \cdot 18 \\
0 \cdot 40\end{array}$ & $\begin{array}{l}0.8-2.8 \\
1.63 \\
0.52\end{array}$ & $\begin{array}{l}1 \cdot 2-5 \cdot 5 \\
3 \cdot 26 \\
1 \cdot 28\end{array}$ \\
\hline Test on variances & \multicolumn{2}{|c|}{$\begin{array}{l}\text { Group } 1 \mathrm{v} \text { group } 2 \\
\mathrm{~F}=1.69, \mathrm{P}>0.05\end{array}$} & $\begin{array}{l}\text { Gious } 3 \text { v group } 4 \\
F=6.11, P<0.01\end{array}$ \\
\hline Test on means & \multicolumn{2}{|c|}{$\mathbf{t}=3.07,0.001<P<0.005$} & $t=4.55, P<0.001^{2}$ \\
\hline
\end{tabular}

Table VIII Circular muscle thickness in ulcerative colitis in patients with faecal stasis and diverticular disease

- Including six patients with diverticular disease and faecal stasis. Range: $1 \cdot 1 \cdot 1 \cdot 9$, m 2 an $1 \cdot 48$, SD 0.26 .

${ }^{2}$ Welch's modification of $t$ test for different variances applied.
Thickness of muscle layers

Information on the thickness of the circular muscle (Fig. 6) of the colon in colitis patients with $\Omega$ faecal stasis, in diverticular disease associated $\stackrel{\odot}{\rightleftharpoons}$ with faecal stasis, and in two control groups of $\overrightarrow{\overrightarrow{\vec{F}}}$ patients with ulcerative colitis without faecal stasis and patients with diverticular disease but no ulcerative colitis is summarized in Table VIII. The last group (diverticular disease) were patients operated upon for the disease. No significant difference appears in the mean values for cir- $\delta$ cular muscle thickness among patients with $\vec{\circ}$ faecal stasis associated with ulcerative colitis whether diverticular disease was present or not $(\mathrm{t}=1.00,0.3<\mathrm{P}<0.4)$ but the patients with faecal stasis alone showed a greater variance $(\mathrm{F}=5.86,0.01<\mathrm{P}<0.05)$. The combined group of all patients with faecal stasis in ulcerative colitis shows a highly significant increase in muscle thickness over the control patients with uncomplicated ulcerative colitis. The second control group of patients with diverticular disease alone show a highly significant increase in muscle thickness as compared with that of the patients with faecal stasis and colitis. An increased variance of muscle thickness was also present in this group.

\section{MOTILITY}

\section{Right colon}

Recordings of motility were obtained when the capsule reached or was just distal to the ileocaecal junction, which was recognized radiologically (Fig. 7), and by the change in the character and the frequency of the waves from an ileal to a colonic pattern. At the ileocaecal junction in normal subjects ileal frequency of waves (7-10 per min) falls to the colonic level ( 2 waves per min). In four subjects with faecal stasis studied the colonic pressure waves were smal in three and in the fourth subject were almost absent. Fluoroscopic examination of the capsule revealed rotational movements but little or no pressure change was recorded; records of the signal strength showed rapid, irregular falls consistent with orientational movements of the capsule (Fig. 8). There appeared to be a loss of propulsion, with the capsule rotating in the faecal stream entering from the terminal ileum. In these four cases the capsule took four to five days at the minimum to pass this area. (The average transit through the right colon in eight normal subjects was six and a half hours.)

In three of the subjects with faecal stasis the basal pressure across the ileocaecal junction dropped as in normals, but remained lower than normal. This contrasted with five patients with colitis without faecal stasis who either showed patterns similar to those of the normal controls or, as in two subjects, revealed a slight rise in basal pressures. 


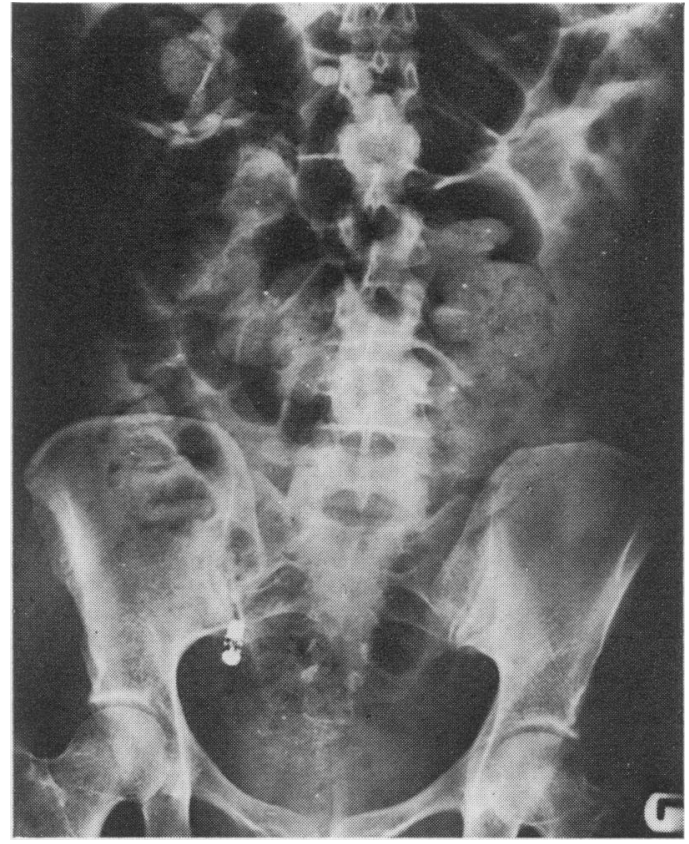

Fig. 7 Telemetering capsule passing from the terminal ileum into the caecum faintly outlined by previous administration of barium most of which by this time had been evacuated.

\section{Left colon}

The mean motility index, defined as the product of the mean wave height in millimetres of water and the percentage duration of waves occurring during the recorded period, was calculated in 14 control subjects. It was found to be 166 in the basal state, 322 for the gastrocolic reflex stimulation, and 806 after prostigmine injection. In five patients with colitis and faecal stasis the mean motility index was 204 in the basal state, 668 after gastrocolic reflex stimulation, and 1,400 after prostigmine. The mean responses to prostigmine in faecal stasis lay between the values for normal subjects given above and for the diverticular disease cases (prostigmine response $=2,856$ ) reported by Attisha and Smith (1969); the gastrocolic response was much less in both groups (mean motility index in faecal stasis 668 and in diverticular disease 740).

\section{Discussion}

Our findings confirm those of Lennard-Jones and his colleagues (1962b). The essential feature in these patients is the hold-up of faeces in the right half of the colon although all patients pass frequent stools consisting in the main of blood and mucopus. Plain abdominal films in patients in whom the frequency of passage of faeces has fallen usually show evidence of stasis in the
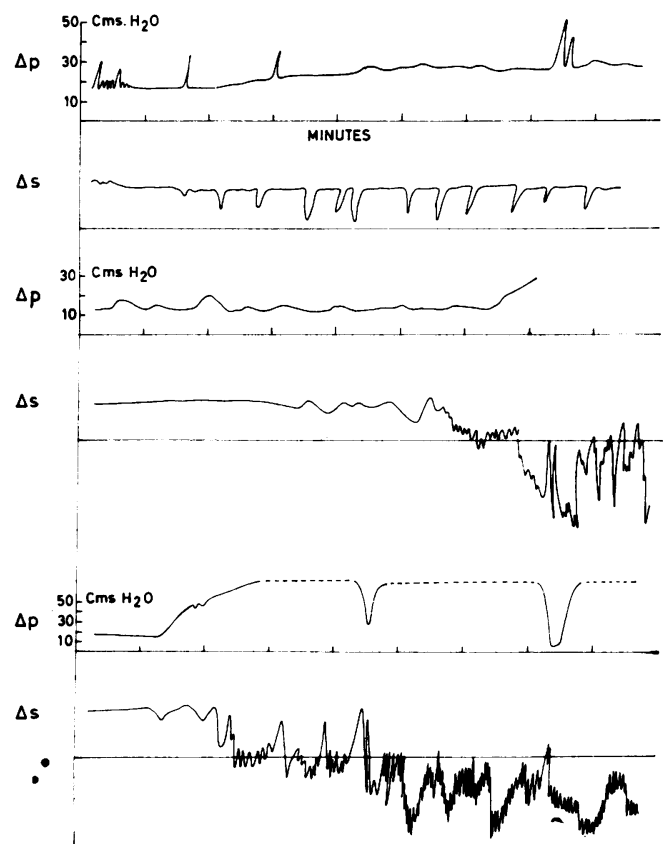

Fig. 8 Pressure activity $(\triangle \mathrm{p})$ and capsule signal strength $(\triangle \mathrm{s})$ recorded from the right colon. The upper set of recordings for pressure and signal strength shows little pressure activity and variability of the signal strength from which can be deduced that there is movement of the capsule. In the subsequent pressure and signal recording underneath there is again little pressure change, and at first, little alteration in the signal strength, but this later becomes irregular showing that there is marked capsular positional change. The final set of recordings of pressure and signal strength shows a rise in basal pressure and marked alteration of signal strength indicating rapid movement of the capsule. At this point observation by radiological 'imageintensification' screening showed some movement. Marked borborygmi indicated distal small bowel activity, and it could be deduced that the capsule rotational effects were taking place in the stream of chyme being forced to flow into the right colon.

proximal colon. Stasis produces disability deserving of treatment in itself. We have found both liquid paraffin and oral dioctylsodium sulphasuccinate to be helpful.

In our experience constipation due to stasis in proctocolitis is usually a transient affair which remits when the inflammation is brought under control but tends to recur with each exacerbation of the disease. In one patient in whom the colitis remained active over a long period barium was still present in the right half of the colon three months after a barium enema.

The incidence of stasis in our series was greatest in patients with limited distal involvement of the colon. This fits the concept discussed by Lennard-Jones et al (1962b) that the cause is a functional obstruction to the passage of 


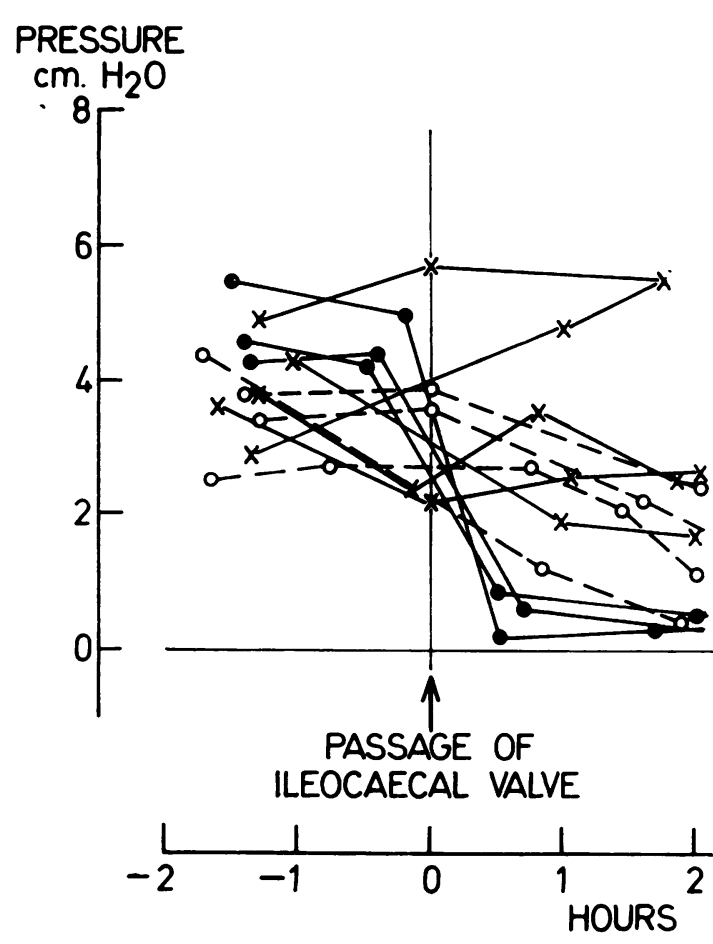

Fig. 9 The basal pressure has been studied in the right colon at the time of a passage of a telemetering capsule from the terminal ileum through the ileocaecal valve into the right colon. It was observed in four normal subjects $(\bigcirc \ldots . .-\bigcirc)$ that the pressure falls. This fall was greater in three subjects with faecal stasis (O- In ulcerative colitis, without stasis $(\times-\times)$, the pressure varied and either fell as in normals or in two instances remained at a high level.

faeces associated with a relatively normal proximal colon retaining the capacity to absorb water so that hard, scybalous masses are formed. On this basis, however, faecal stasis should not occur in the presence of extensive involvement of colon in which faeces remain liquid. However, in our series, seven patients with total involvement of the colon had faecal stasis, and examination of the specimens resected at operation in six of these provided histological confirmation. There was, however, a gradient of disease with the most severe changes occurring distally.

The evidence that diverticular disease is based on disordered motility (Arfwidsson, 1964; Painter and Truelove, 1964; Attisha and Smith, 1969 ) is convincing. To examine the possibility that faecal stasis in colitis had a similar basis, we compared patients with diverticular disease and those with faecal stasis. Nearly $20 \%$ of our colitis patients with faecal stasis gave a previous history of constipation. Symptoms and signs of faecal stasis invariably followed rather than preceded each attack of colitis. In some patients, the fortuitous addition of the disordered motility of diverticular disease to ulcerative colitis could explain the constipation or, alternatively, in the absence of diverticular disease, it seemed possible that ulcerative colitis could bring about a similar disordered motility. On this hypothesis muscles changes might be expected in colitis, and, similaro to those seen in early diverticular disease, possibly음 result in the formation of diverticula.

In the Oxford area the radiological incidence of diverticular disease is in the region of $30 \%$ ino subjects over the age of 60 (Manousos, Truelove, and Lumsden, 1967) and compares with the $25 \%$ incidence in our patients with ulcerative colitis over the age of 60 . In the age group 40-59, theo incidence of diverticular disease in the Oxforde area was $18.5 \%$ compared with $14.3 \%$ for our ulcerative colitis patients in this age group. These figures appear to favour an incidentalo association of the two diseases in our patients $\infty_{\infty}^{\infty}$ but there are certain difficulties with this inter-윽 pretation. The diagnosis of diverticular disease in the presence of ulcerative colitis is not easy? (Berenbaum, Yaghmai, and Berenbaum, 1965). 으 In our six pathological specimens in which the 2 two diseases coexisted diverticula were demon- $\vec{\varphi}$ strated radiologically in only three. It may be relevant that before 1958 only one of $103^{\circ}$ of our patients with colitis was recognized too have diverticular disease, in the following two years nine out of 61 were recognized, and, up to the end of the study, 13 out of 235 cases had $\frac{\Phi}{\Phi}$

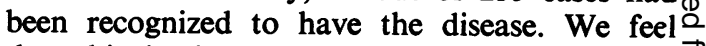
that this is due to more accurate radiological $\overrightarrow{\overrightarrow{0}}$ diagnosis. The true incidence of diverticular disease may be higher than our radiologically based overall figure would suggest.

Although Collins (1961) reported a grave prognosis in patients with ulcerative colitis $\frac{+}{\sigma}$ complicated by acute diverticulitis, we have not 3 . encountered this association.

The pathological study supports the concept that a motility disorder similar to that seen in 0 diverticular disease accounted for the faecal stasis because significant thickening of the inner $\frac{D}{2}$ spiral muscle of the colon was demonstrated. In diverticular disease this is accompanied by $\mathscr{O}$ marked thickening of the taenia which, it has $N$ been suggested, causes bunching of the colon $\underset{\omega}{N}$ with an apparent increase in density of all the 0 colonic elements (Williams, 1968). In our retro- 0

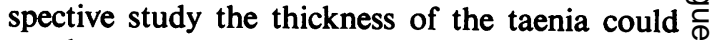
not be measured. Morson (1966) considered the $\stackrel{?}{?}$ characteristic shortening of the bowel in ulcera- $\square$ tive colitis to be due to a muscle abnormality and maintains that fibrosis makes little contribution to the inflammatory response in colitis. Our $\mathbb{D}$ results confirm the presence of muscle abnormality and in only one patient was there a potential organic obstruction. The degree of muscle thickening in the patients with colitis and faecal stasis lay between that in the ordinary colitic population and that found in the group of patients with diverticular disease. Functional abnormality of 
muscle in colitis was suggested by the work of Garrett, Sauer, and Moertel (1967), who showed significant hyperactivity of the pelvic colon in patients with mild or moderate proctocolitis after oral administration of 15 minims of tinct. opii compared with normal controls.

Other motility studies have demonstrated decreased motor activity in patients with ulcerative colitis (Spriggs, Code, Bargen, Curtiss, and Hightower, 1951; Kern, Almy, Abbot, and Bogdonoff, 1951). Kern and his colleagues (1951) had shown an inverse relationship between the frequency of bowel habit and the total activity of the record. Chaudhary and Truelove (1961), on the other hand, suggested that the mean total activity was greater in patients with severe colitis, but Connell (1962), in a discussion of this report, pointed out that this was probably a false interpretation as the results were significantly affected by one patient with abnormally high activity and after excluding this case, the mean total activity for the remainder was less than normal. There has been great variation in the results for individual patients, but in most studies there has been no attempt to divide them on the basis of bowel frequency, and most of the patients studied have had diarrhoea. Kern et al (1951) studied the motility of the distal colon in non-specific ulcerative colitis, and hyperactive records were obtained in four patients, three of whom had constipation. Our own finding of increased activity, mainly after prostigmine stimulation in the left colon in ulcerative colitis associated with faecal stasis in the right colon, is in accord with this, and apparently agrees with our pathological study in that the mean total activity in the sigmoid colon after cholinergic stimulation for these patients fell between that of normals and that found in diverticular disease. The observation of atony and non-propulsion in the proximal colon is in keeping with the proximal dilatation observed in resected specimens and presumably reflects a passive response to the distal functional obstruction; the basal pressure fell at the ileocaecal junction when a rise might have been expected if active obstruction, without atony, had been present. The observations are taken from patients in whom the orientational position of the capsule had not changed and in whom the capsule to aerial radio link had not varied, as indicated by the stability of the strength of the signal received from the capsule.

An interesting histological finding was that the mucosa in many of the diverticula did not share in the inflammatory response of the surrounding mucosa, but we can offer no explanation for this unless disordered motility has some aetiological significance in colitis, as diverticula, being largely free of muscle, can have little share in the motility responses of the rest of the colon.

Our evidence suggests that when ulcerative colitis is associated with faecal stasis a muscular abnormality exists which may be indistinguishable from that seen in prediverticular disease and the irritable colon syndrome. It is possible that this in some cases leads to the formation of diverticula but loss of mucosal tissue due to ulceration would otherwise limit the process.

We wish to thank Mrs L. Lockerbie and the staff of the Computer and Statistics Section of the Department of Social Medicine, University of Edinburgh, for valuable technical assistance.

Dr K. N. Jalan was supported for this work initially by the Scottish Hospital Endowments Research Trust and latterly by Pharmacia (Great Britain) Ltd during the tenure of a research fellowship. Dr W. Sircus is an external member of the scientific staff of the Medical Research Council. Mr A. N. Smith was supported by a grant for motility studies by the Scottish Hospital Endowments Research Trust. We wish to thank Dr Shirley Clarke for assistance with the motility studies.

References

Arfwidsson, S. (1964). Pathogenesis of multiple diverticula in the sigmoid colon in diverticular disease. Acta chir. scand., Suppl., 342.

Attisha, R. P., and Smith, A. N. (1969). Pressure activity of the colon and rectum in diverticular disease before and after sigmoid myotomy. Brit. J. Surg., 56, 891.

Berenbaum, S. L., Yaghmai, M., and Berenbaum, E. R. (1965). Ulcerative colitis in association with diverticular disease of the colon. Radiology, 85, 880-886.

Chaudhary, N. A., and Truelove, S. C. (1961). Human colonic motility: A comparative study of normal subjects, patients with ulcerative colitis, and patients with the irritable colon syndrome. Gastroenterology, 40, 1-17.

Collins, D. C. (1961). The grave prognosis of ulcerative colitis engrafted upon acute diverticulosis coli. Amer. J. Gastroent., 35, 222-229.

Connell, A. M. (1962). The motility of the pelvic colon II. Paradoxical motility in diarrhoea and constipation. Gut, 3, 342-348.

Garrett, J. M., Sauer, W. G., and Moertel, C. G. (1967). Colonic motility in ulcerative colitis after opiate administration. Gastroenterology, 53, 93-100.

Goligher, J. C., de Dombal, F. T., Watts, J. McK., and Watkinson, G. (1968). Ulcerative Colitis, p. 63. Bailliere, Tindall and Cassell, London.

Henderson, N. P. (1954). What is ulcerative colitis? Lancet, 1, 159-160.

Jalan, K. N., Prescott, R. J., Sircus, W. Card, W. I, McManus, J. P. A., Falconer, C. W. A., Small, W. P., and Smith A. N. and Bruce, J. (1969). An experience of ulcerative colitis. II. A clinical study of 399 cases. (In press.)

Kern, F. Almy, T. P., Abbot, M. D., and Bogdonoff, M. D. (1951). Motility of the distal colon in non-specific ulcerative colitis. Gastroenterology, 19, 492-503.

Lennard-Jones, J. E., Cooper, G. W., Newell, A. C., Wilson, C. W. E., and Avery Jones, F. (1962a). Observations on idiopathic proctitis. Gut, 3, 201-206.

Lennard-Jones, J. E., Langman, M. J. S., and Jones, F. A (1962b). Faecal stasis in proctocolitis. Gut, 3, 301-305.

Manousos, O. N., Truelove, S. C., and Lumsden, K. (1967). Prevalence of colonic diverticulosis in general population of Oxford area. Brit. med. J., 3, 762-763.

Morson, B. C. (1966). In Systemic Pathology. (1st Ed.), Ch. 17, pp. 558-559, edited by Payling Wright, G., and Symmers, C. W. Longmans, London.

Nefzger, M. D., and Acheson, E. D. (1963). Ulcerative colitis in the United States Army in 1944. Gut, 4, 183-192. 
Painter, N. S., and Truelove, S. C. (1964). Intraluminal pressure patterns in diverticulosis of colon. Gut, 5, 201-213.

Royal Society of Medicine (1909). Statistics of ulcerative colitis from the London Hospitals. Proc. roy. Soc. Med., 2, II. Med. Cat., 100-106.

Sim, M., and Brooke, B. N. (1958). Ulcerative colitis; a test of psychosomatic hypothesis. Lancet, 2, 125-126.

Smith, A. N., and Ridgway, M. (1962). The use of telemetering capsules in disorders of the alimentary tract. 1. A technique for recording pressure changes. Gut, 3, 366-376.

Spriges, A. E., Code, C. F., Bargen, J. A., Curtiss, R. K., and Hightower, N. C. (1951). Motility of pelvic colon and $\Omega$ rectum in normal persons and patients with ulcerative

colitis. Gastroenterology, 19, 480-491.
Williams, I. (1968). Diverticular disease of the colon. A 1968 जी view. Gut, 9, 498-501.

\section{The July 1970 Issue}

\section{THE JULY 1970 ISSUE CONTAINS THE FOLLOWING PAPERS}

Neurological disorders and adult coeliac disease JOHN S. MORRIS, A. B. AJDUKIEWICZ, AND A. E. READ

The absorption of carbenoxolone administered orally as a positioned-release capsule $\mathbf{W}$. $E$. LINDUP, D. V. PARKE, AND D. COLIN-JONES

A controlled trial of glycopyrronium and 1hyoscyamine in the long-term treatment of duodenal ulcer MICHAEL D. KAYE, J. RHODES, PETER BECK, PETER M. SWEETNAM, G. T. DAVIES, AND K. T. EVANS

The effect on jejunal mucosa of withdrawing and adding dietary gluten in cases of idiopathic steatorrhoea D. J. POLLOCK, R. E. NAGLE, K. N. JEJEEBHOY, AND N. F. COGHILL

Spread of lesions in Crohn's disease of the colon F. BRAHME AND A. WENCKERT

Epsilon-aminocaproic acid therapy in ulcerative colitis R. H. SALTER AND A. E. READ
Fibrinolysis in colonic disease c. H. J. SWAN, J. $\infty_{\infty}^{\infty}$ ALEXANDER WILLIAMS, AND W. T. COOKE

Giant duodenal ulcer K. LUMSDEN, J. $\quad$ c. MaCLARNON, AND J. DAWSON

Studies on the origin of faecal amino acids in cystic fibrosis J. W. T. SEAKINS, R. S. ERSSER, AND I. S. E. GIBBONS

Prolonged survival after portal decompression of patients with non-cirrhotic intrahepatic portal hypertension R. ZEEGEN, A. G. STANSFELD, A. M. DAWSON, AND A. H. HUNT

Calcium palmitate and $a$-palmitic acid in gallstones D. JUNE SUTOR

Progress reports

Radiology of the portal system LOUIS KREEL

Epidemiological evidence for the association of aspirin and acute gastrointestinal bleeding M. J. S. LANGMAN

Notes and activities

Copies are still available and may be obtained from the PUBLISHING MANAGER, BRITISH MEDICAL ASSOCIATION, TAVISTOCK SQUARE, WC1H 9JR price 17s. 6D. 